\title{
Plasma profile of cimicoxib in sheep after oral administration at two different rates
}

\author{
A. Di Salvo', M. Giorgi ${ }^{2}$, H.K. Lee ${ }^{3}$, C. Vercelli ${ }^{4}$, F. Rueca ${ }^{1}$, \\ M. Trabalza Marinucci, G. della Rocca ${ }^{1}$ \\ ${ }^{1}$ Department of Veterinary Medicine, University of Perugia, Perugia, Italy \\ ${ }^{2}$ Department of Veterinary Sciences, University of Pisa, Pisa, Italy \\ ${ }^{3}$ Pharmacology and Toxicology, College of Veterinary Medicine, Chungnam University, Daejon, South Korea \\ ${ }^{4}$ Department of Veterinary Sciences, University of Torino, Grugliasco, Torino, Italy
}

\begin{abstract}
Sheep are often subjected to painful procedures and thus they need to be treated with analgesics. Nevertheless, knowledges about pharmacokinetic features of these drugs in this species are poor. The aim of this study was to evaluate plasma behaviour of cimicoxib in sheep after a single oral administration at two different dose rates ( 4 and $6 \mathrm{mg} / \mathrm{kg}$ ). Maximum plasma concentrations of cimicoxib were equal to 273.78 (median value; range 189.00-567.32) and 565.01 (range 308.27-822.59) ng/mL after treatment with 4 and $6 \mathrm{mg} / \mathrm{kg}$, respectively. The time of maximum concentration $\left(\mathrm{T}_{\max }\right)$ was achieved between 4 and 10 hours following treatment at the lower dose, and between 6 and 10 hours after the administration of the higher dose, with one sheep achieving the concentration peak at 0.75 hours.

The slow absorption and the great individual variability in plasma concentration, probably due to ruminal effects, suggest that cimicoxib is not suitable for oral treatment in sheep.
\end{abstract}

Key words: cimicoxib, oral administration, pharmacokinetics, sheep

\section{Introduction}

Sheep are frequently submitted to painful procedures, such as castration, mulesing and tail-docking, or can be affected by painful pathologies, such as mastitis and footrot (Stubsjøen et al. 2009). Moreover, this species is commonly used as an experimental animal model for particularly invasive surgeries (Coulter et al. 2009).

Few analgesic drugs are registered for sheep. Several countries allow the use of drugs licensed for others species, but this off-label use is often limited by the paucity of knowledge regarding the pharmacokinetics, efficacy and residue depletion of the drug in this animal species. Another limitation to pain management in sheep is the difficulty in administering injectable drugs; an oral analgesic drug administered with feed would simplify pain treatment in sheep (Marini et al. 2015)

Nonsteroidal anti-inflammatory drugs (NSAIDs) are a large class of drugs used as analgesics in various animal species. The analgesic efficacy of this class of drugs has been reported in sheep suffering from footrot or undergoing castration and tail-docking (Welsh

Correspondence to: A. Di Salvo, e-mail: alessandra.disalvo@unipg.it 
and Nolan 1995, Small et al. 2014). NSAIDs may involve adverse side effects, especially related to the gastrointestinal tract. In recent decades, it has been suggested that a preferential selectivity of these drugs towards COX-2 enzymes could be associated with a minor incidence of this adverse side effect (Harirforoosh et al. 2013). Consequently, a new class of drugs named coxibs, selective COX-2 inhibitors, has appeared on the market. Cimicoxib belongs to this group and is licensed for oral use as an anti-inflammatory and analgesic drug in dogs.

Potentially, this drug could be efficiently used in species other than the dog like the sheep, even if the absence of a value of Maximum Residue Limit would limit the use to experimental animals and sheep in wool production. However, the pharmacokinetic and pharmacodynamic differences among animal species, especially between ruminants and monogastric species, require studies to elucidate the behaviour of the drug in the systemic circulation and its efficacy in the destination species.

The aim of this study was to evaluate the pharmacokinetics of cimicoxib after oral administration in sheep at two different dose rates (4 and $6 \mathrm{mg} / \mathrm{kg}$ ). The choice to test higher doses of cimicoxib than that recommended for dogs $(2 \mathrm{mg} / \mathrm{kg})$, followed the knowledge that sheep ruminal microflora, by metabolising part of the drugs, could reduce their bioavailability (Baggot and Brown 1998). In a recent study, carprofen, flunixin and ketoprofen were administered orally to sheep at a dose two times higher than that reported for intravenous administration in previous studies, in order to avoid the potential reduction of the bioavailability operated by the ruminal environment (Marini et al. 2015). The administration of cimicoxib in large animals has been reported only in the equine species (horses and donkeys) (Kim et al. 2014, Kim et al. 2015). In both studies, the drug was orally dosed at $5 \mathrm{mg} / \mathrm{kg}$, as plasma concentrations of cimicoxib appeared to be very low following a pilot study conducted in horses, where $2 \mathrm{mg} / \mathrm{kg}$ were administered.

\section{Materials and Methods}

Six Sarda ewes, weighing between 33-54 kg, were enrolled in the study, which was approved by the Bioethical Committee of the University of Perugia (protocol number: 2013-034), in accordance with the EC Council Directive 86/609 EEC on the protection of animals used for experimental and other scientific purposes.

Ewes, considered healthy on the basis of clinical examination and biochemical profile, were randomly divided in two groups (three subjects/group) and allocated to two indoor pens 5 days before the study, in order to provide a sufficient time of acclimation.

A balling gun was used to treat sheep orally with two different doses (4 and $6 \mathrm{mg} / \mathrm{kg}$ ) of cimicoxib (Cimalgex $80 \mathrm{mg}$, Vetoquinol, Lure, France), according to a cross-over design ( 2 X 2 Latin square), with a washout period of 2 weeks between the two treatments. The drug was administered after 20 hours of fasting, and 4 hours after the treatment the animals were fed commercial pelleted concentrate and meadow hay. Water was available ad libitum for the entire experimental period.

Blood samples were collected at prefixed time points (before treatment and after 0.25, 0.5, 0.75, 1, $1.5,2,4,6,8,10$ and 24 hours) from the jugular vein. Blood was placed in lithium heparinised tubes and plasma obtained after centrifugation was frozen and maintained at $-80^{\circ} \mathrm{C}$ until the analysis. The plasma concentrations of cimicoxib were assessed using a previously published analytical method (Giorgi et al. 2013), and briefly revalidated in sheep plasma.

The $\mathrm{C}_{\max }$ and $\mathrm{T}_{\max }$ values were obtained from the observed data and AUCs by linear trapezoidal rules.

\section{Results}

Following treatment with $4 \mathrm{mg} / \mathrm{kg}$ of cimicoxib, the drug was detectable in the systemic circulation from 1 hour post administration in three animals, 1.5 hours in one subject and 4 hours in the last two sheep of the group. The $\mathrm{C}_{\max }(273.78 \mathrm{ng} / \mathrm{mL}$, median value) was achieved between 4-10 hours post administration; the concentrations then dropped gradually, and cimicoxib was still detectable in four up to 6 animals at 24 hours.

Following treatment with $6 \mathrm{mg} / \mathrm{kg}$ of cimicoxib, the drug started to be detectable in plasma between 0.25 and $2 \mathrm{~h}$. The $\mathrm{C}_{\max }(565.01 \mathrm{ng} / \mathrm{mL}$, median value) was achieved at 8 and 10 hours post administration in two and three animals, respectively. The last subject of the group presented the first detectable drug plasma concentration at 0.25 hours, the peak concentration $(536.08 \mathrm{ng} / \mathrm{mL})$ at 0.75 hours, a concentration drop $(52.04 \mathrm{ng} / \mathrm{mL})$ at 4 hours and an important secondary peak $(404.13 \mathrm{ng} / \mathrm{mL})$ at 6 hours. A double peak was also observed in two animals treated with $6 \mathrm{mg} / \mathrm{kg}$.

Figure 1 shows the mean cimicoxib concentrations vs. time profiles following the two treatments.

Table 1 resumes the $\mathrm{C}_{\max }, \mathrm{T}_{\max }$ and $\mathrm{AUC}_{0 \text {-last }}$ values obtained following oral administration of cimicoxib at the two dose rates. No other pharmacokinetic parameters were calculated, due to the lack of sufficient available points needed to determine the terminal phase. 


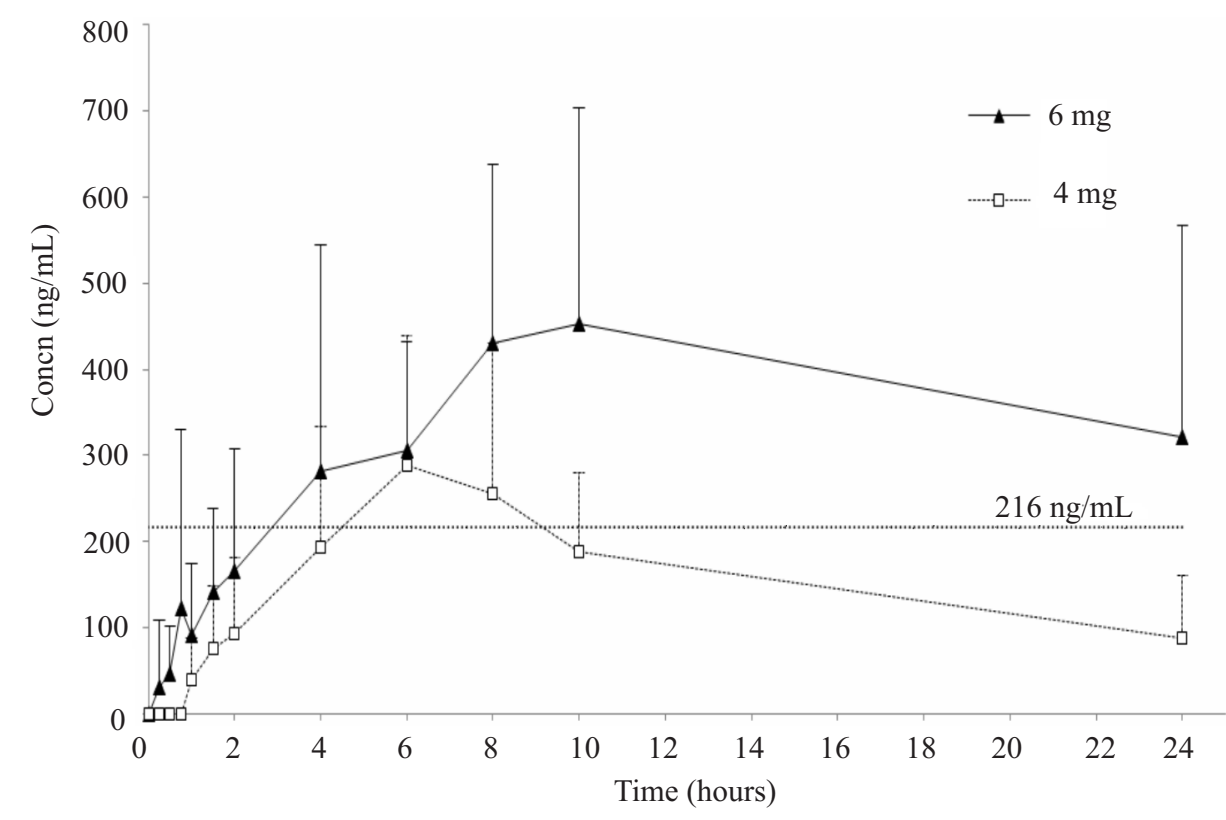

Fig. 1. Mean plasma concentration of cimicoxib following oral administration at $4 \mathrm{mg} / \mathrm{kg}$ and $6 \mathrm{mg} / \mathrm{kg}$ in six sheep. Bars represent Standard Deviation.

Table 1. $T_{\max }, C_{\max }$ and AUCs values calculated after oral administration of cimicoxib at $4 \mathrm{mg} / \mathrm{Kg}$ and $6 \mathrm{mg} / \mathrm{kg}$ in six sheep.

\begin{tabular}{lcc}
\hline \multicolumn{1}{c}{ Parameter } & $4 \mathrm{mg} / \mathrm{kg}$ median value (range) & $6 \mathrm{mg} / \mathrm{kg}$ median value (range) \\
\hline $\mathrm{T}_{\max }(\mathrm{h})$ & $6(4-10)$ & $9(0.75-10)$ \\
\hline $\mathrm{C}_{\max }(\mathrm{ng} / \mathrm{mL})$ & $273.78(189.00-567.32)$ & $565.01(308.27-822.59)$ \\
\hline $\mathrm{AUC}_{0 \text {-last }}\left(\mathrm{ng} / \mathrm{mL}^{*} \mathrm{~h}\right)$ & $2957.71(1626.36-6771.86)$ & $8680.47(1951.38-11281.99)$ \\
\hline
\end{tabular}

AUC $_{0 \text {-last: }}$ area under concentration-time curve; $\mathrm{C}_{\max }=$ Maximum observed concentration; $\mathrm{T}_{\max }=$ Time of maximum observed concentration.

\section{Discussion}

Cimicoxib appeared in the systemic circulation in a variable amount of time, ranging from 1 to 4 hours in sheep treated with $4 \mathrm{mg} / \mathrm{kg}$ and from 0.25 to 2 hours after administration of $6 \mathrm{mg} / \mathrm{kg}$. The $\mathrm{T}_{\max }$ was obtained at a median value of 6 and 9 hours after administration of 4 and $6 \mathrm{mg} / \mathrm{kg}$, respectively. A possible cause of the slow rate of absorption of cimicoxib in sheep could be the dilution of the drug in the large volume of ruminal fluids (Baggot and Brown 1998). A very slow absorption after oral administration in sheep was also observed for another NSAID, Meloxicam, which achieved the $\mathrm{C}_{\max }$ at 19 hours (Stock et al. 2013). Another explanation for the long time required to obtain the $\mathrm{C}_{\max }$ might be a possible binding of cimicoxib to the hay residues in the rumen. Even if sheep were fasted for several hours, it is known that the rumen is never completely empty. Another study also suggested that cimicoxib may bind with feed, and observed a delayed $\mathrm{C}_{\max }$ after oral administration of cimicoxib in fed with respect to fasted horse (Kim et al. 2015). Other NSAIDs (phenylbutazone and flunixin) have also been previously hypothesised to bind with hay (Lees et al. 1988a).

The increase of the $\mathrm{C}_{\max }$ obtained following the administration of $6 \mathrm{mg} / \mathrm{kg}$ of cimicoxib compared to the value observed after the $4 \mathrm{mg} / \mathrm{kg}$ treatment was directly proportional to the increase in the dose. However, a large variability among sheep was observed in both treatments, as attested by the standard deviation shown in Fig. 1. This individual variability could be due to different amounts of fibrous feed remaining in the rumen at the time of administration. This condition may also be responsible for the secondary peaks observed in some animals: while one part of the drug is absorbed into the bloodstream, another part may bind to feed in the rumen and subsequently untie from the hay due to the fermentative process and be adsorbed to produce a secondary peak (Lees et al. 1988b). As in the dog cimicoxib is mainly excreted through the bile (EMA 2011), it is also possible to hypothesise that the secondary peak could be the consequence of enterohepatic circulation due to biliary excretion in sheep. 
The $\mathrm{AUC}_{0 \text {-last }}$ value obtained after the administration of $6 \mathrm{mg} / \mathrm{kg}$ is greater than the value expected with the dose increase, when compared to the value obtained after treatment with the lower dose. An overestimated AUC might have been calculated after treatment with the higher dose due to a paucity of sampling data in the elimination phase of the curve (Toutain and Bousquet-Melou 2004): in fact, with a $\mathrm{T}_{\max }$ obtained between 8 and 10 hours in the majority of the subjects, only one or two useful sampling times were available to delineate the final phase of the curve.

Another limitation of this study is the absence of the intravenous treatment useful to define the bioavailability of cimicoxib after oral administration, but this drug is scarcely soluble in water and an injectable formulation is not currently available.

No current data are available on the efficacy of the treatment with cimicoxib in sheep and no studies have been performed to establish the selectivity of this drug on the COXs in sheep. An efficacious plasma concentration of cimicoxib, above or equal to 216 $\mathrm{ng} / \mathrm{mL}$, has been reported in dogs (EMA 2011). This concentration was achieved in sheep at approximately 3 and 5 hours, and maintained for 20 and 4 hours after administering cimicoxib at 6 and $4 \mathrm{mg} / \mathrm{kg}$, respectively (Fig. 1). If the same plasma concentration would be effective in sheep, the drug could be administered 3 hours before the painful procedure at the dose of $6 \mathrm{mg} / \mathrm{kg}$, and its effect would last for over 20 hours. However, the great variability in the absorption of cimicoxib in sheep suggests that the treatment is unpredictable. Therefore, the drug is probably not suitable for oral treatment in ovine.

\section{Acknowledgements}

Authors would like to thank Vetoquinol Italia S.r.l to have supplied the cimicoxib used for treatments as well as pure cimicoxib for the HPLC analyses.

\section{References}

Baggot JD, Brown SA (1998) Basis for selection of the dosage form. In: Hardee GE, Baggot JD (eds) Development and Formulation of Veterinary Dosage Forms, 2nd ed., Marcel Dekker Inc, New York, pp 7-143.

Coulter CA, Flecknell PA, Richardson CA (2009) Reported analgesic administration to rabbits, pigs, sheep, dogs and non-human primates undergoing experimental surgical procedures. Lab Anim 43: 232-238.

EMA, (2011). European Medicine Agency. Cimalgex: EPAR - Public assessment report. EMA/CVMP/513842/ 2011.

Giorgi M, Kim TW, Saba A, Rouini M-R, Yun H, Ryschanova R, Owen $\mathrm{H}$ (2013) Detection and quantification of cimicoxib, a novel COX-2 inhibitor, in canine plasma by HPLC with spectrofluorimetric detection: development and validation of a new methodology. J Pharm Biomed Anal 83: 28-33.

Harirforoosh S, Asghar W, Jamali F (2013) Adverse effects of nonsteroidal antiinflammatory drugs: an update of gastrointestinal, cardiovascular and renal complications. J Pharm Pharm Sci 16: 821-847.

Kim TW, Della Rocca G, Di Salvo A, Owen H, Sgorbini M, Giorgi M (2014) Pharmacokinetics of the Novel Cyclooxygenase 2 Inhibitor Cimicoxib in Donkeys. J Equine Vet Sci 34: 923-925.

Kim TW, Della Rocca G, Di Salvo A, Ryschanova R, Sgorbini M, Giorgi M (2015) Evaluation of pharmacokinetic and pharmacodynamic properties of cimicoxib in fasted and fed horses. N Z Vet J 63: 92-97.

Lees P, Taylor JB, Higgins AJ, Sedgwick AD (1988a) In vitro and in vivo binding of phenylbutazone and related drugs to equine feeds and digesta. Res Vet Sci 44: 50-56.

Lees P, Ayliffe T, Maitho TE, Taylor JB (1988b) Pharmacokinetics, metabolism and excretion of phenylbutazone in cattle following intravenous, intramuscular and oral administration. Res Vet Sci 44: 57-67.

Marini D, Pippia J, Colditz IG, Hinch G, Petherick JC, Lee C (2015) Randomised trial of the bioavailability and efficacy of orally administered flunixin, carprofen and ketoprofen in a pain model in sheep. Aust Vet $\mathbf{J}$ 93: 265-270.

Small AH, Belson S, Holm M, Colditz IG (2014) Efficacy of a buccal meloxicam formulation for pain relief in Merino lambs undergoing knife castration and tail docking in a randomised field trial. Aust Vet J 92: 381-388.

Stock ML, Coetzee JF, KuKanich B, Smith BI (2013) Pharmacokinetics of intravenously and orally administered meloxicam in sheep. Am J Vet Res 74: 779-783.

Stubsjøen SM, Flø AS, Moe RO, Janczak AM, Skjerve E, Valle PS, Zanella AJ (2009) Exploring non-invasive methods to assess pain in sheep. Physiol Behav 98: 640-648.

Toutain PL, Bousquet-Mélou A (2004) Bioavailability and its assessment. J Vet Pharmacol Ther 27: 455-466.

Welsh EM, Nolan AM (1995) Effect of flunixin meglumine on the thresholds to mechanical stimulation in healthy and lame sheep. Res Vet Sci 58: 61-66. 